\title{
La configuración narrativa del paratexto en Conquista Espiritual del Paraguay de Antonio Ruiz de Montoya
}

\begin{abstract}
Marcela Nélida Pezzuto ${ }^{1}$
El presente artículo analiza la variedad de discursos del paratexto de Conquista Espiritual, que colaboran en la comprensión textual. Dicho paratexto (cartas, exhortatorio y dedicatoria) constituyen el marco que encierra y ancla el significado de la crónica-informe. Estudiaremos los diferentes textos contrastándolos entre sí para comprobar la univocidad del sujeto de la enunciación. Abordaremos los enunciados como actos perlocutivos para analizarlos desde su fuerza ilocutiva. Es decir, realizaremos un camino de comprensión textual desde los elementos denotativos hasta llegar a los componentes connotativos de la obra. Nuestra metodología comprenderá estudios de actos de habla, principio de relevancia y de cooperación, así como la argumentación. La reflexión discursiva permitió observar la relación que existe entre lengua y sociedad. Nuestro concepto de base consiste en la interacción comunicativa como un producto social de la facultad del lenguaje. Así, al estudiar el lenguaje, es posible analizar las expresiones lingüísticas en un contexto social como parte de una cultura.
\end{abstract}

\section{El discurso de la crónica y el relato}

Consideramos al lenguaje como una función del ser humano que, a partir de la imagen, realiza una configuración del mundo. En otras palabras, el lenguaje es la configuración lingüística del mundo. La comprensión del mundo se transmite a través de las palabras estableciendo el lenguaje, entonces, el límite y el perfil del conocimiento humano. También es necesario agregar que la representación del mundo está marcada por la captación personal del mismo. Por ello, el lenguaje es percepción subjetiva y configuración mediatizada por la verbalización.

El producto de la comprensión del mundo a través del lenguaje resulta ser una expresión lingüística marcada por un mensaje intencional pensado por un determinado sujeto en un determinado momento y lugar.

1 Argentina. Doctora en Letras, Pontificia Universidad Católica Argentina "Santa María de los Buenos Aires". Académica del Departamento de Filosofía y Letras, Pontificia Universidad Católica Argentina "Santa María de los Buenos Aires". E-mail: marcelapezzuto@gmail.com 
La crónica del Padre Montoya se presenta con un fuerte vínculo con el relato histórico que, como tal, guarda estrechas relaciones con el concepto de verdad. El tipo discursivo informe que emplea garantizaba la veracidad de las narraciones de las experiencias evangelizadoras de los religiosos. Sin embargo, es posible observar en la obra Conquista Espiritual marcas evidentes de una subjetividad que sostiene el relato y manifiesta su visión del mundo. Esta voz se esfuerza en presentarse como testigo y, a la vez, manifiesta su fidelidad a los sucesos. Dicha perspectiva de objetividad se basa en un discurso de características asertivas estructurado en función de certezas. Montoya relata lo que sucedió en la región de la Paraquaria, pero lo interesante es que aquello que sucedió, es digno de contarse y en la acción de contar hay necesariamente un recorte de lo que se considera importante. De hecho, es imposible que Montoya narre todo. Es evidente que solamente contará lo que mereció su atención. Así, el informe que produce resulta un texto con ciertos acontecimientos que aparecen viabilizados a través de la narración que implica una selección de hechos, un ordenamiento y una interpretación. Todo esto refiere a la experiencia personal de la voz narradora sobre los sucesos descritos. Por lo cual, a partir de la concepción de la realidad histórica buscamos develar la construcción retórica de Montoya. Esta se encuentra marcada por la intencionalidad del autor que busca reivindicar la acción de los padres jesuitas entre las poblaciones indígenas y solicitar la defensa de esos grupos: "Estas cosas, contadas por mayor, fueron la causa de mi venida á la fuente de la justicia y reales piés, empleo para mí dichoso, que con esperanza firme espero el debido remedio para aquellas ovejas que gozando de sus vegas (sus tierras digo) que la naturaleza les repartió, usen de la libertad común á todos, y reconociendo con el tributo que su pobreza alcanza, vivan amparados del poderoso brazo con que su Majestad..." (Montoya [1639] 1989: 276).

Nuestra perspectiva se centra en estudiar el campo de las palabras, el léxico, la semántica y la intencionalidad. En particular, tomaremos la unidad frase como un fenómeno de interrelaciones por lo que involucra a varios individuos en un acontecimiento histórico, intentando producir un efecto en el receptor. Así, analizaremos la situación comunicativa. Para cumplir este objetivo es necesario presentar el recorte con el que trabajaremos.

En Conquista Espiritual se identifican seis textos que componen el paratexto:

1) "Aprobación del muy llustre Señor el Doctor Don Lorenzo de Mendoza, Prelado del Rio de Genero" (Montoya: 41-42) [PAR1]

2) "Dedicatoria a Octavio Centurion, Marques de Monasterio" (Montoya: 43) [PAR2]

3) "Exhortatorio que hizo el ilustrísimo Señor Obispo de Tucumán a nuestra Congregación" (Montoya: 277-279) [PAR3] 
4) "Carta que escribió el mismo señor Obispo a su Majestad" (Montoya: 279-282) [PAR4]

5) "Pónense dos capítulos de una carta de D. Pedro Esteban Dávila, gobernador de Buenos Aires, para su Majestad" (Montoya: 283-285) [PAR5]

6) "Pónese aquí una cédula real" (Montoya: 286-288) [PAR6]

Este material aparece organizado de la siguiente manera: [PAR1] y [PAR2] al inicio del libro, a continuación de la portada y [PAR3]; [PAR4]; [PAR5] y [PAR6] luego del cierre que le da Montoya al relato de la destrucción de las reducciones a manos de las bandeiras portuguesas: "El número de gente que llevaron no se sabe, algo se rastreará por el diezmo que pagaron á la iglesia; 500 personas dieron al Religioso por su parte, al modo que el ganadero paga el diezmo de ovejas ó de vacas; cupieron al clérigo 200." (Montoya [1639] 1989: 276).

Nuestro marco teórico consistirá en estudios propios de la pragmalingüística, es decir, los actos de habla, estructuras discursivas y relaciones que se evidencian entre los hablantes, el discurso y el contexto. Nos centraremos también en la importancia de la situación comunicativa que influye en la interpretación de los significados. Por otro lado, a partir de la sociolingüística observaremos las relaciones entre el lenguaje y la sociedad. De esta forma, la reflexión lingüística sobre la estructura discursiva de Montoya nos permitirá descubrir su constitución, la intencionalidad y las regulaciones que aparecen a través de representaciones cognitivas, razonamientos, normatividades, evaluaciones y descripciones.

El concepto de discurso constituye la base de la que partimos ya que representa una práctica social de naturaleza simbólica en la que está incluido el componente y también el significado. También todo discurso carga una información implícita, es decir, significados adicionales a los significados explícitos. Al respecto nos proponemos, por un lado, develar lo que inferiría todo lector de la época de Montoya y, por el otro, reconocer la intención del enunciador (Montoya). Para alcanzar este objetivo hemos considerado los siguientes aspectos del paratexto: 1) el significado explícito de los enunciados; 2) el conocimiento que comparten emisor y receptor; 3) el contexto situacional; 4) la intención del hablante, y 5) el significado implícito.

Si bien nos referiremos a todos los aspectos enumerados, será en el último punto, es decir, en la información implícita en donde nos detendremos para estudiar la información intencional, inferida y contextual, es decir, aquella que es deducida del contexto y de las palabras empleadas. Dichos significados implícitos sumados a los significados literales, los encadenamientos de la argumentación y las implicaturas (Ducrot, 1974 y Grice, 1995) que aparecen en el recorte textual nos permitirán buscar el conocimiento del mundo de 
Montoya. Será, entonces, a partir de estos conceptos que intentaremos profundizar en el universo del jesuita, rescatando la información que maneja a partir de sus intereses personales y valoraciones respecto de la idea del bien, de lo bello y de lo verdadero. En definitiva, nos proponemos sacar a la luz las relaciones de poder que instituye Montoya en sus enunciados.

Al comenzar a abordar Conquista Espiritual resulta necesario trabajar en primer lugar sobre los conceptos de enunciación como la actividad del lenguaje ejercida por quien habla en el momento en que habla, es decir, con carácter histórico y de proceso. Y también de enunciado que constituye el acto de poner en funcionamiento a la lengua en uso individual. El enunciado es el objeto de la enunciación, una realidad empírica que se presenta para ser interpretada. Constituye una manifestación, un producto lingüístico. Por otra parte, la enunciación remite siempre a la subjetividad ya que supone la conversión individual de la lengua en discurso. Por lo tanto, para analizar el discurso es necesario analizar quién produce los sentidos, en qué circunstancias, con qué medios o instrumentos, a quién está dirigido y con qué intencionalidad.

Iniciaremos con el concepto de discurso considerado como la relación dialéctica entre proposiciones y el referente. Partimos de que todo discurso asume una posición explícita respecto de determinados asuntos, por lo cual se presenta con una postura social y, en cierta medida, política. Todo discurso pretende generar conocimiento y opinión y tiene como objetivo realizar cambios de tipo social que se presentan como resistencia hacia ciertos tipos de dominación (Van Dijk, 1999: 24). Y se encuentra conformado por diferentes enunciados que en nuestro texto guardan una compleja relación entre el sujeto empírico que produce el enunciado (SE) y el responsable de la enunciación en el enunciado (L).

Para comprender cabalmente el discurso de Montoya en primer lugar citaremos las voces (SE, L) y los diferentes enunciados (e) que conforman el discurso (d) del paratexto.

\section{Tabla 1}

\begin{tabular}{|l|l|l|l|l|l|}
\hline [PAR1] (d1) & [PAR2] (d2) & [PAR3] (d3) & [PAR4] (d4) & [PAR5] (d5) & [PAR6] (d6) \\
\hline $\begin{array}{l}\text { SE } \\
\text { Don } \\
\begin{array}{l}\text { Lorenzo } \\
\text { de Men- } \\
\text { doza }\end{array}\end{array}$ & $\begin{array}{l}\text { SE } \\
\text { Antonio Ruiz } \\
\text { de } \\
\text { Montoya }\end{array}$ & $\begin{array}{l}\text { SE } \\
\text { Montoya/ } \\
\text { Obispo de } \\
\text { Tucumán, } \\
\text { Fray Melchor } \\
\text { Maldonado }\end{array}$ & $\begin{array}{l}\text { SE } \\
\text { Obispo de } \\
\text { Tucumán/ } \\
\text { Montoya }\end{array}$ & $\begin{array}{l}\text { SE } \\
\text { Gobernador } \\
\text { Pedro E. Dávila/ } \\
\text { Montoya/ } \\
\text { Lic. Andrés León } \\
\text { Garavito }\end{array}$ & $\begin{array}{l}\text { SE } \\
\text { Montoya/ Rey }\end{array}$ \\
\hline L Montoya & L Montoya & L Montoya & L Montoya & L Montoya & L Montoya \\
\hline $\begin{array}{l}\text { (e) } \\
\text { afirmar/ } \\
\text { valorar }\end{array}$ & $\begin{array}{l}\text { (e) } \\
\text { ofrecimiento/ } \\
\text { agradecimien- } \\
\text { to/ } \\
\text { homenaje }\end{array}$ & $\begin{array}{l}\text { (e) } \\
\text { cuidado/ } \\
\text { interés en } \\
\text { evangelización }\end{array}$ & $\begin{array}{l}\text { (e) } \\
\text { solicitar religio- } \\
\text { sos/ } \\
\text { solicitar dinero } \\
\text { para evange- } \\
\text { lizar }\end{array}$ & $\begin{array}{l}\text { (e) } \\
\text { lemencia y } \\
\text { piedad del rey }\end{array}$ & $\begin{array}{l}\text { (e) } \\
\text { regulación del } \\
\text { servicio } \\
\text { personal de } \\
\text { indígenas }\end{array}$ \\
\hline
\end{tabular}




\section{La crónica y el relato desde una reflexión lingüística}

La estructura discursiva de los seis paratextos está conformada a partir de enunciados (acto locutivo) que constituyen oraciones (forma gramatical que toma el acto locutivo). Para ello observaremos la estructura interna de los discursos y luego las relaciones en la argumentación.

El paratexto, recorte de nuestro estudio, como acto locutivo posee una finalidad perlocutiva, motivo por el cual las voces que aparecen no hacen más que demostrar que tienen tanto la instancia de enunciación en que se pone en funcionamiento la lengua, como su producto, los enunciados. Así, Montoya aparece siempre como L (locutor) responsable de la enunciación en el enunciado y apela a otros sujetos (agentes enunciadores) que construyeron enunciados SE (sujeto del enunciado) y que son cartas, informes, cédulas reales, etc. En otras ocasiones, el propio Montoya no toma palabras ajenas adueñándoselas, sino que las produce él mismo; sin embargo, gracias a esta estrategia Montoya adquiere una gran competencia como hablante.

Estas voces de la enunciación constituyen un acto ilocutivo revelando las intenciones del hablante Montoya que buscan, en definitiva, provocar un efecto. Por medio de las palabras en las proposiciones se observan las relaciones necesarias entre las ideas.

Partiremos de cada enunciado considerándolo bajo la categoría de apropiado, y desde la teoría de los actos de habla, a partir del acto ilocutorio cuya función es modificar la situación y circunstancias de los interlocutores. Es decir, nos centraremos en su hacer. Nos centraremos en las oraciones como hechos reales, como acontecimientos del habla.

[PAR1] APROBACIÓN DEL MUY ILUSTRE SEÑOR EL DOCTOR DON LORENZO DE MENDOZA, PRELADO DEL RIO DE GENERO

Este primer discurso inicia su título con la acción /aprobar/, con lo cual este juicio de valor caracteriza a todo el enunciado como asertivo. Cobra especial relieve que el SE o agente enunciador sea don Lorenzo de Mendoza, Prelado de Río de Janeiro. La importancia del /muy ilustre señor/ que realiza un elogio de la obra de Montoya lo hace merecedor de inaugurar la obra.

Los factores contextuales relevantes de este discurso son:

- Situación: lugar (Río de Janeiro), tiempo "Después de haber visto...los libros del tesoro, Arte, Vocabulario, y Catecismo de la lengua Guaraní del Paraguay..." y "Me mandó de nuevo el dicho Real Consejo, que viese, y examinase esta obra del dicho Padre Antonio Ruiz de Montoya, intitulada: Relación de la conquista Espiritual...". En tercer lugar "...Mayo 16 de 1639." 
- Contexto socio-cultural/personas presentes y tipo de relación: Instancia de obediencia entre prelado y rey. Felipe IV señala la lectura para emitir parecer de la obra "...por mandado del real y Supremo Consejo de su Majestad...".

- Información/Significado explícito: 1) Los libros escritos por el padre Antonio Ruiz de Montoya ofrecen datos relevantes sobre las regiones del Perú y del Río de la Plata. 2) Acciones benévolas realizadas por los religiosos de la Compañía de Jesús en domesticación, reducción y conversión de gentiles. 3) Padecimientos y logros de los padres jesuitas. 4) Justificación de su impresión.

- Emisor: don Lorenzo de Mendoza.

- Destinatario: Felipe IV e imprenta real.

- Enunciado y tono del mensaje: el discurso se presenta como un acto declarativo: "Y digo, que no solamente no contiene cosa alguna contra nuestra santa Fe (...) se ve lo mucho que Dios ha obrado por medio del celo y trabajos, y predicación de los dichos religiosos..."

En el acto de/decir/ de parte del SE se observan los siguientes enunciados:

(e1) "...fundaron en las dichas Provincias un jardín de flores de cielo, y una nueva, y primitiva Iglesia, que el lobo del infierno por tantas vías ha pretendido destruir..." /jardín/ /flores del cielo/ - /lobo/ /infierno/

En el acto de /ser buen testigo/ de parte del SE se observan:

(e2) "...yo soy buen testigo, por estar las dichas reducciones tan conjuntas con mi Diócesis. Y así... lo que se padece de pobreza, y otros grandes trabajos, por los dichos Religiosos..."

/desiertos, breñas, selvas, montañas/ - /fieras humanas/

Y en la unión entre ambas acciones "decir" y "ver" se estructura este primer acto locutivo declarativo cuya consecuencia redunda en tres conceptos elogiosos:

/obras heróicas//Provincia de la Compañía "Plus omnibus laboravi"//es justo que se imprima/

-Significado Implícito: En cuanto construcción efectiva, la carta se basa en el siguiente mensaje: Imprimir el libro de Montoya por el mérito de la obra realizada por los jesuitas, en general, y por Montoya, en particular. A partir de la economía semántica (Anscombre y Ducrot, 1994: 79) se produce un escalonamiento de la interpretación por medio de la graduación de su contenido:

/Celo / trabajo / predicación / 
/domesticación /reducción /conversión/

/pobreza /grandes trabajos/

Por otra parte, el SE, obispo Lorenzo de Mendoza, basa además su autoridad en un elemento intelectual: saber = ser testigo

Tabla 2

\begin{tabular}{|l|l|}
\hline saber & /saber cómo son las reducciones/ \\
\hline & /saber lo que se padece de pobreza/ \\
\hline & /saber lo que se ha hecho/ \\
\hline & /saber padecimiento de trabajos/ \\
\hline & /saber que no hay riquezas/ /no hay comodidades/ \\
\hline
\end{tabular}

Este hecho de /saber/ lleva al SE a concluir con un acto cortés expresivo: /Plus omnibus laboravi/

En otras palabras, el acto locutivo del prelado (SE) es asumido por Montoya (L) para producir un acto perlocutivo: alcanzar la publicación y que ésta demuestre todo lo que los padres jesuitas lograron en la Paraquaria.

Como acto elocutivo este primer texto apunta a modificar la situación del L locutor Montoya, es decir, que se lo valore y aprecie. De esta forma a través del decir del SE sujeto empírico se pretende una transformación en el hacer del L locutor.

\section{[PAR2] DEDICATORIA A OCTAVIO CENTURIÓN, MARQUÉS DE MONASTERIO}

La afirmación con que comienza la dedicatoria marca el tono de todo el segundo discurso: /Logro es del don topar con quien lo estime/. Por el tono casi conceptista de este primer acto cortés expresivo se puede considerar la dedicatoria como un ofrecimiento, un agradecimiento y también encierra un halago hacia el destinatario, el Marqués de Monasterio. Sin embargo, para contrarrestar ese efecto grandilocuente Montoya incluye otro acto asertivo: /Este pequeñuelo que ofrezco/

En este texto aparece el SE, Montoya, que coincide con el L. A través de la $1{ }^{\text {a }}$ persona Ruiz de Montoya se asume como responsable de la enunciación en el enunciado.

Los factores contextuales del discurso son:

- Situación: Lugar (Corte en Madrid) tiempo (no se especifica aunque existen elementos para relacionarlo cercano a la fecha de impresión a fines de junio de 1639). 
- Contexto socio-cultural/personas presentes y tipo de relación: Instancia de ofrecimiento y humildad de Montoya ante Octavio Centurión.

- Información/Significado explícito: 1) aumento de la piedad, de la misericordia y de la devoción del Marqués. 2) deseo de agradar a Dios.

- Emisor: Antonio Ruiz de Montoya.

- Destinatario: Octavio Centurión, Marqués de Monasterio.

- Enunciado y tono del mensaje: El discurso se presenta como un acto expresivo (cumplidos) y también como acto comisivo (promesas). Respecto de los primeros: "Logro es del don topar con quien lo estime"; "piadoso celo"; " misericordia"; " devoción"; " deseo de agradar a Dios"; "afabilidad y favor".

En cuanto a las promesas: "Este pequeñuelo (...) se le promete muy grande"; "La piedad (...) no dude se llene de espiritual alegría"; "gozarase de ver cómo se funda la Iglesia".

En el acto locutivo de Montoya cobran importancia dos tipos de enunciados: (e1) que hacen referencia a las acciones de Montoya y de los jesuitas y (e2) acciones del Marqués de Monasterio.

(e1a) "los maravillosos hechos de Dios entre Gentiles,..."

(e1b) "tan gloriosos trofeos de la Fe,..."

(e1c) "...que naciones tan bárbaras hayan conocido a su Criador y Redentor Jesucristo."

(e1d) "Materia desto represento (...) en tan gloriosos trabajos, y servicios que se han hecho a Dios, y a la Iglesia..."

(e1e) "...se funda la Iglesia en las regiones que estaban en la sombra de la muerte, y las puertas del infierno..."

(e1f) "...como se exalta la Fe, como se vence al demonio, como se redimen las almas."

(e2a) "No se estrecha el deseo que V.S. tiene de agradar a Dios a solo lo que hace..."

(e2b) "Templos funda V.S. y santos monasterios, para que llene la gloria de su título humano..."

En la unión entre/promesa/y /cumplido/ se estructura el acto exhortativo (el encargo de la obra) en base a una herramienta racional: "El argumento 
es digno de la piedad de V.S. ...". Este enunciado /argumentar/ no consiste en la demostración formal que valida la veracidad de la conclusión, sino que forma parte de la estructura interna de los enunciados con un valor persuasivo que no necesariamente guarda relación con la lógica.

- Significado Implícito: La construcción de la dedicatoria (acto perlocutivo) se basa en el siguiente mensaje: el libro está dedicado a una persona piadosa, devota, misericordiosa y poderosa. Dentro de esta relación hay una subordinación del L: /humilde capellán/ /el afecto de su autor/

frente al $D$ (destinatario): /hombre de piadoso celo//gloria del título humano/ /hombre afable/

Con estos argumentos Montoya reclama un nuevo favor de Centurión: aceptar el libro "Conquista Espiritual".

[PAR3] EXHORTATORIO QUE HIZO EL ILUSTRÍSIMO SEÑOR OBISPO DE TUCUMÁN A NUESTRA CONGREGACIÓN

El discurso consiste en un aviso con la finalidad de persuadir. Varios son los actores que conforman el enunciado: por un lado, el Obispo de Tucumán y, por el otro, Montoya. En este -junto con los siguientes- comienza un cambio en la modalidad de la construcción de la enunciación. Montoya no será solamente el $\mathrm{L}$, es decir, el responsable de la enunciación en el enunciado y que asume como propio el enunciado de otros, sino también él producirá los suyos, lo cual lo hace SE.

Respecto de esto es importante observar que inicia el discurso con una afirmación rotunda: "La peligrosa carga de un Obispo (si se mide bien) es intolerable, y mucho más si esta es de gentiles." El tono de estas primeras palabras posiciona desde el comienzo de la carta el peso del L, Montoya, en la enunciación. Sin embargo, en la regulación del discurso, hay una marca gráfica (las comillas) que diferencia la voz de Fray Melchor Maldonado: "Representó su celo en un exhortatorio que presentó a la Congregación, y es el siguiente..."

Los factores contextuales relevantes de este discurso son:

- Situación: lugar (Provincia de Tucumán), tiempo (1637)²

2 Se colige que el Exhortatorio del Obispo de Tucumán al Provincial Diego de Boroa se realizó en 1637 porque hay documentación probatoria de la realización de la sexta Congregación. Nota 229, p. 277 de la edición de 1989: “Al margen dice: Juntóse Congregación a 20 de julio de 1637. Alude a la sexta congregación de la provincia jesuítica del Paraguay, reunida en esa fecha en Córdoba." 
- Contexto socio-cultural/personas presentes y tipo de relación: Instancia de reconocimiento hacia la Compañía de Jesús. Intervienen el Obispo de Tucumán y el Padre Diego Boroa. El vínculo entre ellos consiste en que el obispo se vale de los jesuitas en la tarea evangelizadora ("...para cumplir con su obligación y ejecutar su celo, valerse del de nuestra Compañía").

- Información/Significado explícito: 1) En la introducción a la carta Montoya destaca los trabajos entre gentiles y el cuidado, la diligencia y el interés del obispo en cuestiones de evangelización. 2) Necesidad de religiosos para tareas de conversión. 3) Exhortación al Provincial a continuar con la prédica.

- Emisor: Fray Melchor Maldonado de Saavedra.

- Destinatario: Padre Provincial Diego Boroa.

- Enunciado y tono del mensaje: el discurso se presenta como un acto de habla exhortativo no impositivo en el que prima la exhortación a continuar en la tarea evangelizadora "...ir corriendo las doctrinas, valles, estancias y términos donde hubiere gente convertida y bautizada, que vayan confesando, predicando y administrando los Sacramentos y el del matrimonio, haciendo oficio de curas...".

En el acto de /exhortar/ de parte del SE se observan los siguientes enunciados:

(e1) "Los obispados del Paraguay, Tucumán y Buenos Aires están rodeados de provincias dellos, que al llustrísimo de Tucumán le fue forzoso para cumplir con su obligación y ejecutar su celo, valerse del de nuestra Compañía (de que dan claro testimonio 94.990 gentiles que por el bautismo tiene agregados á la Iglesia, sin los que desde el año de 36 hasta hoy ha ido bautizando)."

/celo del Obispo//celo de la Compañía de Jesús/

(e2) "...la necesidad grande que en esta provincia hay de ministros evangélicos, (...) es tan grande la falta de operarios..."

/necesidad/

(e3) "...hemos conocido muchas faltas irremediables (...) de que hemos dado cuenta a su Majestad, y se la damos a su Santidad."

/faltas irremediables/

(e4) ". ...Jesucristo Señor nuestro (...) nos ha de juzgar, premiándonos en juicio o castigándonos, según nuestras obras..." 
/juicio según actos/

(e5) "...teniendo la satisfacción que tenemos de la Compañía de Jesús y del celo con que cuida la honra de Dios y de la conversión de las almas...", "...rogamos que haga a nuestro Señor y a su Iglesia este servicio."

/satisfacción de la Compañía//promesa de continuar servicio/

(e6) "...escoja los sujetos que hallare más capaces, y les cometa la predicación del santo Evangelio..."

/sujetos capaces/

- Significado Implícito: La carta como enunciado contextualizado posee el siguiente mensaje que se presenta en un escalonamiento de la interpretación por medio de la graduación del contenido: comienza halagando a Fray Melchor Maldonado por el peligro de evangelizar entre gentiles. Luego, se menciona la necesidad de predicadores sin faltas puesto que recibirán juicio divino. A continuación, se insta a los miembros de la Compañía a seguir con la evangelización.

/evangelizadores sin faltas//trabajo satisfactorio de jesuitas/ /continuar con conversión/

En esta carta también el SE, el Obispo de Tucumán, basa su autoridad en el elemento intelectual: saber. "Sabrá V.P., como bien debe saber, y le tenemos comunicado, y entre los dos conferido..."

Tabla 3

\begin{tabular}{|l|l|}
\hline Saber & $\begin{array}{l}\text { /saber la necesidad de ministros evangélicos//saber que no hay gente } \\
\text { bautizada/ }\end{array}$ \\
\hline & /saber que hay pocos clérigos en grandes territorios/ \\
\hline
\end{tabular}

Este hecho de /saber/ lleva al SE a continuar con un acto cortés expresivo: /teniendo la satisfacción de la Compañía de Jesús y del celo con que cuida la honra de Dios/.

Debemos destacar que el hecho de "saber" se ve reforzado por el "deber saber", con lo cual el conocimiento adquiere la impronta de obligación moral por el "deber".

Hacia el final del segundo párrafo el obispo afirma: " ... donde no pudiéremos por nuestra persona, lo debemos encargar y fiar á personas dignas...". Esta afirmación abre el elogio hacia los jesuitas: 
/personas dignas//celo/ /cuidan la honra de Dios/ /cuidan la conversión de almas/

Estas palabras concluyen con el recordatorio de la promesa realizada por el Provincial:

lasí nos lo tiene prometido V. Paternidad/

que cede lugar al exhorto del Obispo:

/exhortamos de parte de su Majestad/y /exhortamos de parte de Dios/

Cada uno de los exhortos está presentado siguiendo un gradualismo compromisivo:

\section{/Majestad//Dios/}

Y al referirse a cada uno de los actores emplea la fórmula: nominación + atributo

/Majestad, Patrón destas Iglesias/ /Dios, Señor que sólo puede pagar con igualdad de mérito de tan grande obra/

El cierre de la carta del SE Obispo de Tucumán refuerza el acto perlocutivo de evangelizar. Para ello recurre a las siguientes acciones:

/han de ir a repartirse por todas esas diócesis/ /escoja los sujetos que hallare más capaces/

/les cometa la predicación á los infieles/

Finalmente, el Obispo señala un último acto de validación de la tarea evangelizadora:

/que a los que V. Paternidad aprobare y señalare para los dichos efectos desde luego les señalamos, y aprobamos, y damos el poder en derecho necesario, como lo tenemos para todo lo sobredicho, y descargamos en esto nuestra conciencia con la de V. Paternidad/.

La inclusión de esta instancia de enunciación posee una doble función: destacar a la Orden Jesuita, en general, y a la persona de Montoya, en particular, a partir de la propia obra evangelizadora y de la producción escrita.

\section{[PAR4] CARTA QUE ESCRIBIÓ EL MISMO OBISPO A SU MAJESTAD}

En este extenso discurso el L Montoya retoma el mismo SE por tratarse como un actor influyente que, en esta ocasión, se dirige directamente al rey. El enunciado comienza con la acción /mandar/, es decir, es un acto directivo 
exhortativo que resulta apropiado para el agente real. El asunto que se "manda" es información que está relacionada con: "...la necesidad en que este obispado de Tucumán hubiere de Religiosos, para ayuda de la predicación evangélica y conversión de indios..."

Los factores contextuales de este discurso son:

- Situación: lugar (Córdoba, en ocasión de la sexta Congregación de la provincia jesuítica del Paraguay), tiempo "Agosto 11 de 1637."

- Contexto socio-cultural/personas presentes y tipo de relación: Instancia de obediencia entre el obispo de Tucumán y Felipe IV: " ...Manda vuestra Majestad por su real carta...".

- Información/Significado explícito: 1) Extensión de la provincia, cantidad de ciudades pobladas y de habitantes. 2) Carencia de religiosos para atender a ocho doctrinas. 3) Sacerdotes seglares con faltas; franciscanos escasos; jesuitas con caridad y ejemplaridad. 4) Solicitud de enviar predicadores al Chaco y a la provincia para proteger a los indígenas de "mestizos, castellanos y portugueses (...) y por los moradores de San Pablo (...) ayudados de los tupis". 5) Pedido de cuarenta religiosos.

- Emisor: Fray Melchor Maldonado de Saavedra.

- Destinatario: Felipe IV.

- Enunciado y tono del mensaje: el discurso se presenta como un acto asertivo "...informe de la necesidad en que este obispado de Tucumán hubiere de religiosos..." y exhortativo "...pido a vuestra Majestad por las entrañas de Dios..."

El SE destaca que a partir del /conocimiento/ es posible/informar/ "...con el conocimiento de más de tres años que ha que entré a esta obispado, y haber andado las cuatro partes del, las tres visitándole personalmente, en que he andado casi 300 leguas..." como se observa en los siguientes enunciados:

(e1) "...hay de 12.000 a 14.000 almas, muchos de ellos bautizados, hoy apóstatas de la fe, porque con la falta de la doctrina (...) se vuelve (...) a sus antiguos ritos e idolatrías. Otros senos tiene con más de 50.000 almas, donde ha tenido principios la predicación evangélica por religiosos de la Compañía de Jesús, y se dejó por el mal gobierno de unos españoles que entraron con las armas a conquistar aquella parte...".

/bautizados/ - /apóstatas/ /Religiosos de la Compañía de Jesús/ - /españoles/ (e2) "...hay más de ocho doctrinas que de ninguna manera tienen cura que los confiese y doctrine, (...) "Yo no puedo estar en todas partes; de 
donde resulta la condenación de muchas almas redimidas con la sangre de Cristo nuestro Señor, y que están debajo del amparo de vuestra Majestad y a mi cuidado."

/no confesión//no doctrina//condenación de almas/ /cuidado del obispo/ /cuidado de Majestad/

(e3) "En las reducciones donde hay sacerdotes seglares hay muchisimas faltas irremediables; (...) la de San Francisco tiene pocos sujetos, con que apenas puede servirse en sus coros. La Compañía de Jesús (...) en las ciudades, de día y de noche acuden a doctrinas y confesar enfermos..."

/Sacerdotes seglares - faltas/ /franciscanos - pocos/ /jesuitas - acuden, confiesan/

(e4) "Y hoy he pedido en nombre de vuestra majestad al Provincial de la religión de la Compañía (...) que envíe al Chaco predicadores evangélicos, para que sin armas, y con la predicación evangélica veamos si podemos alcanzar de Dios nuestro Señor la conversión de aquellas gentes (...) Religiosos misioneros (...) a un tiempo están padeciendo el odio doméstico de los mismos castellanos de aquel obispado por el amparo que dan a los indios (...) y por los moradores de San Pablo del Brasil, ayudados de los tupis..."

/jesuitas misioneros predicadores odiados / - /castellanos, de San Pablo, tupíes perseguidores/

Todos estos enunciados concluyen en un último enunciado (e5) /pedir/: "Atento a lo cual humildemente pido a vuestra Majestad..."

Esta acción de pedir consiste en:

"Se compadezca desta miserable nacion"

"me ayude con su larga y poderosa mano a conseguirlo [salvación]"

"concediendo a esta Religión 40 Religiosos"

"Y es cierto, Señor, que si no estuviera empeñado en gastos de mi oficio, y con renta tan corta (...) Vuestra Majestad mandará lo que fuere servido"

El pedido de religiosos jesuitas y de dinero presenta la siguiente graduación argumentativa:

compadecerse / ayudar / conceder religiosos / conceder renta

- Significado Implícito: La carta como enunciado contextualizado en la relación entre el rey y la iglesia coloca la justa responsabilidad a ambos. 
Por la parte de la iglesia, Fray Melchor Maldonado asume /Yo no puedo

estar en todas partes/ ; /están a mi cuidado/.

Sin embargo, para Felipe IV le cabe /que están debajo del amparo de vuestra Majestad/ ; /patrón destas iglesias/ ; /Cristo nuestro Señor fió de vuestra Majestad la salvación destos indios/.

A continuación, en un último párrafo aparece el L, como sujeto que asume la responsabilidad de la enunciación. Montoya suma su voz en un halago a los cuidados del obispo y de otros responsables por los indígenas. Sin embargo, con notable discreción no menciona a la figura real.

[PAR5] PÓNENSE DOS CAPÍTULOS DE UNA CARTA DE D. PEDRO ESTEBAN DÁVILA, GOBERNADOR DE BUENOS AIRES, PARA SU MAJESTAD

En la enunciación que construye Ruiz de Montoya (L) aparecen tres componentes novedosos, la presencia de tres SE. Por un lado, el gobernador de Buenos Aires, Pedro Dávila, dirigiéndose al rey (dos fragmentos de la carta de 12/10/1637), por el otro, el visitador y juez de residencia, Andrés de León Garavito, con la relación que también enviara al monarca (dos capítulos del Memorial discursivo escrito entre 1631 y 1634) y, por último, el propio Montoya, que interviene directamente con enunciados propios.

La situación comunicativa que se produce en este paratexto es la siguiente:

Tabla 4

\begin{tabular}{|l|l|}
\hline L & $\begin{array}{l}\text { Montoya: "Pónense dos capítulos de una carta de D. Pedro Estéban Dávila. } \\
\text { Gobernador de Buenos Aires, para su Majestad." }\end{array}$ \\
\hline SE 1 & Pedro E. Dávila \\
\hline SE 2 & Montoya \\
\hline SE 1 & Pedro E. Dávila \\
\hline SE 2 & Montoya \\
\hline SE 3 & Andrés de León Garabito \\
\hline L & $\begin{array}{l}\text { Montoya: "Fácil cosa hubiera sido en la visita descubrir el oro; pero ¿cómo } \\
\text { lo habían de descubrir, no lo habiendo? Por lo menos la verdad se descubre } \\
\text { ella, cuando la mañosa emulación quiere disfrazarla." }\end{array}$ \\
\hline
\end{tabular}

Los factores contextuales destacados del primer discurso del gobernador (SE1) son:

- Situación: lugar (Buenos Aires), tiempo "...Octubre 12 de 1637."

- Contexto socio-cultural/personas presentes y tipo de relación: Instancia de informe por parte del gobernador Dávila a Felipe IV. 
- Información/Significado explícito: 1) Daños y perjuicios sufridos en las reducciones jesuitas del Paraguay, Uruguay y del Tape por parte de los vecinos de San Pablo. 2) Viaje del gobernador al río Genero y verificación de esclavitud de vasallos de la Corona española. 3) Exhorto al gobernador portugués, Martin de Sá. 4) Pedido de remedio a Felipe IV y verificación de los hechos por el testimonio del "P. Antonio Ruiz, de la Compañía de Jesús...".

- Emisor: Gobernador Pedro Esteban Dávila.

- Destinatario: Felipe IV.

- Enunciado y tono del mensaje: el discurso se presenta como un acto asertivo.

De parte del SE1 se observan los siguientes enunciados:

(e1) "Fuí advertido de las reducciones o misiones (...) y los daños que recibían de los vecinos de la villa de San Pablo, (...) Y llegado que fuí al río de Genero, vi y reconocí ser cierta la relación que se me había hecho,..."

Necinos de San Pablo/ /daños/ - /indios/ /esclavos/

(e2) "...y deseando el remedio desto exhorté a Martin de Sá, gobernador..."

/remedio/ /exhorto/

(e3) "...más largamente podrá informar a vuestra Majestad el P. Antonio Ruiz..."

/P. Montoya/ /información/

Los factores contextuales del segundo discurso de Dávila (SE1) que posee características asertivas:

- Información/Significado explícito: 1) Provincias fértiles y abundantes. Creencia infundada de hallar metales y cosas preciosas.

/falta de verdad en informes al rey//confusa noticia/ /incierta relación/ / vivas diligencias, de que no surtió efecto alguno/

En la página 284 y 285 (Montoya [1639] 1989) aparece intercalado el SE2 (Montoya).

El primer discurso presenta los siguientes factores contextuales:

- Situación: lugar (Corte española), tiempo (1639) 
- Contexto socio-cultural/personas presentes y tipo de relación: Instancia de informe.

- Información/Significado explícito: 1) Referencia a Conquista Espiritual en donde se informaba de la falta de metales de los indígenas. 2) Defensa ante falso testimonio respecto de bienes colectivos y personales de Montoya. 3) Reconocimiento de las palabras verdaderas del gobernador Dávila.

- Emisor: Antonio Ruiz de Montoya.

- Destinatario: Felipe IV.

- Enunciado y tono del mensaje: el discurso se presenta como un acto declarativo a través de testimonios.

Los enunciados de este SE2 son:

/acto descriptivo verdadero/ - / acto descriptivo falso/

/falta de oro y de plata que tiene aquesta gente/ vs. /deseo común de que lo tuviesen/

Frente a esta situación contradictoria, Montoya estructura una argumentación basada en: 1) la transcripción de dos opiniones de dos testigos:

/afirmaron había arroyos y montes de oro/ /yo era el que gozaba desta grandeza y la ocultaba/

2) la confirmación evidente de las afirmaciones:

/juraron en tres tribunales (...) que era falsa imposición que les ponían/

3) la apelación al SE1 Dávila a partir de la aseveración del concepto de / verdad/ que lo involucra:

/la verdad escribe D. Pedro Estéban Dávila//solícito servidor de su Majestad/ /hizo las diligencias debidas/

El segundo discurso del SE2 representa un acto asertivo /mi verdad/ y exhortativo:

/que aquella provincia se visite, pidiéndolo y rogándolo á los gobernadores/.

El significado explícito tiene dos acciones:

1) Pedir un visitador a la provincia para observar la verdad. 
2) Introducción del Memorial de Andrés de León Garavito como visitador y juez de residencia del gobernador de Buenos Aires.

El discurso del Licenciado Garavito SE3 posee el siguiente contexto:

- Situación: lugar (Buenos Aires), tiempo (1631-16343)

- Contexto socio-cultural/personas presentes y tipo de relación: Instancia de informe

- Información/Significado explícito: 1) Pedido con muchos oficios de los padres jesuitas de visitar poblados para tasarlos.

- Emisor: D. Andrés de León Garavito.

- Destinatario: Felipe IV.

- Enunciado y tono del mensaje: el discurso se presenta como un acto declarativo.

Los enunciados de este SE3 son:

/tiempo que asistí en Buenos-Aires/ /propusieron los Padres visitar poblaciones/ /di cuenta al Consejo, virrey del Perú, y Audiencia de la Plata/ / continuando los padres con muchos oficios, por desear la visita//nunca se resolvió/

Para finalizar el discurso Montoya $L$ asume nuevamente la enunciación con un enunciado asertivo en el que nuevamente aparece la tensión entre verdad-mentira:

/visita para descubrir oro//verdad descubre/ - /emulación disfraza/

[PAR6] PÓNESE AQUÍ UNA CÉDULA REAL

Nuevamente Montoya inicia este último documento como el locutor (L). Su voz regulando el discurso comienza con un acto expresivo en el que destaca la acción del rey:

/celo/ /amparo/ /plena libertad//honra con título de vasallos/

A su vez, constituye también un acto compromisivo porque el bienestar de los indígenas como vasallos del monarca representa la responsabilidad del monarca.

3 Según edición del Equipo Difusor de Estudios de Historia Iberoamericana: "...Memorial discursivo, escrito por el visitador Andrés de León Garavito, que se publicó en Madrid en 1635, (...) Fue persona afecta a los jesuitas y en ese Memorial establecía criterios para el futuro pago del tributo de los indios guaraníes de las reducciones." Montoya: 285. 
La segunda acción que se evidencia es la del propio L: /quiero poner por remate desta obra/. Estas palabras señalan que la escritura de Conquista Espiritual estuvo pensada, estructurada a partir de una formación. La validez de la presentación de este documento legal del rey hablando en primera persona le otorga una fuerza locutiva cuyo objetivo es producir una orden que alcanza significaciones mayores por tratarse del mandato real.

El discurso presenta los siguientes factores contextuales:

- Situación: lugar (Madrid), tiempo (1633).

- Contexto socio-cultural/personas presentes y tipo de relación: Felipe IV se dirige al Virrey del Perú4. Instancia de mandato y encargo.

- Información/Significado explícito: 1) Por ordenanzas se mandó que indígenas sirvan como vasallos libres, que cese el servicio personal y que los tributos para los indígenas sean en dinero o en especies. 2) Permanencia del servicio personal con perjuicios hacia los indígenas produce disminución de población. 3) Mandato de eliminar el servicio personal y consultar con personas desinteresadas cómo se pueden estimar los tributos de los indígenas. 4) Ejecución de la tasación. 5) Envío al rey el nuevo padrón de indios con las nuevas tasas de tributos. Caso de no hacerlo, los responsables pagarán con sus bienes y haciendas.

- Destinatario: Virrey del Perú /a la persona o personas a cuyo cargo fuere su gobierno/

- Enunciado y tono del mensaje: el discurso se presenta como un acto exhortativo impositivo.

Los enunciados son:

(e1) "Bien sabéis que por muchas cédulas y ordenanzas mías (...) se ha mandado que los indios (...) tengan y gocen entera libertad..."

/saber - mandado - libertad/

(e2) "...sabéis, que por repugnar a esto el servicio personal (...) los han tasado en vez de tributo, que pagan (...) a sus encomenderos..."

/saber - tasar - tributo/

4 Aparece también en la instancia del enunciado el secretario del rey D. Fernando Ruiz de Contreras, caballero de la Orden de Santiago, del Consejo de Guerra y de la Cámara de Indias, secretario de Estado de la parte de España y del Despacho Universal. 
(e3) "...está ordenado y mandado apretada y repetidamente que cese y se quite del todo el dicho servicio personal..."

(e4) "... he sido informado que en esas provincias y en otras duran todavía los dichos servicios personales con graves daños y vejaciones de los indios, (...) con codicia desordenada, por cuya causa los dichos indios se huyen, enferman y mueren..."

/servicios personales - daños y vejaciones para indios/

/codicia - indios huyen - indios enferman - indios mueren/

(e5) "...he tenido por bien de ordenar y mandar (...) tratéis de alzar y quitar precisa e inviolablemente el dicho servicio personal..."

/ordenar y mandar quitar servicio personal/

(e6) "...os juntaréis (...) personas entendidas y desinteresadas (...) y platicaréis y conferiréis en qué frutos, cosas y especies se pueden tasar y estimar cómodamente los tributos de los dichos indios..."

/personas entendidas y desinteresadas tasar tributos de indios/

(e7) "Y si sucediere caso de vacar alguna encomienda de las así tasadas en servicios personal, suspenderéis el proveerlas, hasta que con efecto esté hecha la tasa; y el que la entrare a gozar de nuevo, la reciba con ese cargo..."

/encomienda vacante debe tasar nuevamente tributo de indios/

(e8) "...me avisaréis en la primera ocasión y me enviaréis la relación y padrón de los dichos indios y nuevas tasas, con apercibimiento que de cualquier tardanza, omisión o disimulación que en esto hubiere me tendré por deservido..."

/enviar relación y padrón de tasas de indios/

/no enviar relación y padrón de tasas de indios/ - /de servir al rey/

- Significado Implícito: El empleo de un documento legal como era la Cédula Real refuerza el concepto de mandato, encargo. Como instrumento jurídico tiene validez prescriptiva puesto que marca pauta de conducta o, de lo contrario, punición. Es por ello que constituye un acto exhortativo en el que prima la instrucción.

Es interesante observar cómo el $\mathrm{L}$ se vale de este instrumento para construir un mandato, una orden que tiene validez por corresponder a las palabras del propio monarca, autoridad máxima. 


\section{La crónica y el relato desde una reflexión sociolingüística}

El lenguaje constituye una mediación entre mentes y cosas, y por ello representa un mundo en sí mismo. El lenguaje constituye discursos y el mensaje inherente a estos le da realidad al propio lenguaje porque sólo los actos del discurso actualizan el código. Por otra parte, la utilización de un enunciado y su comunicación es un fenómeno interindividual, un acontecimiento histórico en las relaciones de varios individuos: el locutor lo emplea porque la situación en la que se encuentra y ante las personas que lo rodean (real o virtualmente) lo conduce y/o lo autoriza. Además, debemos agregar que siempre hay una intención de causar un efecto en quienes escuchan (Anscombre y Ducrot, 1994).

Así, todo discurso (enunciados que conforman una enunciación) introduce el concepto de dialéctica, el intercambio intersubjetivo por el hecho de hacerse público como experiencia de un hablante. Esta manera de manifestación que poseen las palabras en un discurso guarda intrínsecamente un conflicto que se dirime entre /explicar/ y /comprender/ puesto que la lengua en uso significa algo más allá que la capacidad de hablar. Constituye una estructura particular del sistema lingüístico particular.

Existe una interesante relación entre código y mensaje. Por un lado, el código es colectivo, anónimo y no intencionado; es inconsciente en el sentido de un inconsciente estructural y cultural. También es sistemático y obligatorio para una comunidad de hablantes. Por otra parte, el mensaje es individual, intencional, es decir, pensado por un individuo. Además, se caracteriza por arbitrario y contingente. El mensaje le otorga finalmente realidad al lenguaje porque es a través de los actos del discurso que se actualiza el lenguaje.

Es así que siguiendo una teoría tradicional de sentido, el lenguaje describe la realidad, con lo cual las palabras representan la realidad y por eso poseen un valor denotativo. Según esto, las palabras cargan un valor informativo, motivo por el cual pueden ser estudiadas en función de categorías de verdad o falsedad, llevando a estudiar la función representativa del lenguaje bajo condiciones de verdad del enunciado. Sin embargo, esta perspectiva (sólo estudiar la función informativa) deja de lado otro elemento importantísimo para la cabal comprensión de todo enunciado. Nos referimos al componente argumentativo que involucra necesariamente la participación del receptor con una serie de implicaciones de sentido que aporta desde su propia individualidad y circunstancia histórica. El concepto de implicatura nos será más que válido ya que no sólo interpreta el habla como intercambio de significados, sino como un suceso intersubjetivo en el que intervienen diferentes tipos de relaciones interhumanas, como las relaciones de poder. 
Por esto, el estudio de la lengua es una realidad que permite el debate entre individuos, es un instrumento polémico que sirve a la interacción de los sujetos: "La langue, indepéndamment des utilisations que l'on peut faire d'elle, se presente fondamentalement comme le lieu du débat et de la confrontation des subjectivités" (Ducrot, 1984:31).

El estudio de los enunciados que conforman un discurso posee dos tipos de informaciones: una de tipo explícito (que antes hemos llamado simplemente información) y otra de tipo implícito que constituye los significados adicionales que infiere el lector a partir del reconocimiento de las intenciones del hablante.

Para comprender mejor qué queremos decir con la información explícita es necesario tener en cuenta: a) el significado literal del enunciado; b) el conocimiento que comparten hablante y oyente; c) contexto situacional. En cuanto a la información implícita se caracteriza por: a) es información intencional; b) es información inferida y contextual (deducida del contexto y de las palabras); c) se forma secundariamente luego de rechazar como único el significado literal del mensaje y, finalmente, d) no es información que corrija o niegue la información explícita, sino que sólo añade otros datos.

Cuando un hablante establece una comunicación tiene por objetivo ofrecerle al receptor una determinada información y para ello realiza una jerarquización que lleva al ordenamiento de los contenidos de manera que sean lo más pertinentes posibles y lo más expresivos respecto de aquello que desea transmitir. Esto hace que el hablante utilice medios argumentativos como estructuras causa-consecuencia, enumeraciones de argumentos seguidos de conclusiones. También puede emplear afirmaciones seguidas de ejemplificaciones con el fin de privilegiar determinada información. Consideramos el concepto de argumentación la acción de dar razones para llegar a una conclusión: "Pour nous en effect, un locuteur fait une argumentation lorsqu'il présente un énoncé $E 1$ (ou un ensemble d'énoncés) comme destiné à en faire admettre un autre (ou un ensemble d'autres) E2." (Ducrot, 1984: 18) De hecho, es la propia forma lingüística que poseen los enunciados y no sus factores contextuales o la información que aportan lo que determina el carácter argumentativo: "Les enchaînements argumentatifs posibles dans un discours sont liés à la structure linguistique des énoncés et non aux seules informations quïls vehiculent." (Ducrot, 1984: 9).

Así, argumentar es un conjunto de actividades de parte del productor /L para guiar y anticipar la interpretación del receptor. De acuerdo a Fuentes Rodríguez (1995: 61), dichas actividades son:

- Inferencia: inferir una conclusión opera sobre lo sobreentendido o implícito, es un proceso de generalización. Cuando una proposición es sugerida por otra o por la situación, se habla de argumentación. 
- Mirada argumentativa: ciertos elementos semánticos ${ }^{5}$ de un texto que llevan a hacer admitir una u otra conclusión.

- Acto de argumentación.

- Orientación argumentativa: refiere a la visión de los hechos introducidos por los enunciados portadores de "mirada argumentativa". Refleja la relación entre argumento y conclusión preexistente al momento de la comunicación. En este punto es necesario mencionar el concepto de topos como el principio general que hace posible arribar a una conclusión, una regla que se presupone admitida que tiene un carácter gradual.

De esta forma, la argumentación está apoyada en lugares comunes, en "conocimientos compartidos por la comunidad". Esto es lo que la caracteriza como polifónica, es decir, convocadora de otras voces. A partir de "lugares comunes", de topos, se generan inferencias que remiten a la vox publica, a la comunidad.

Debemos mencionar otra idea relacionada con la polifonía para ampliar nuestro marco teórico. Por ello citamos al dialoguismo bajtiano (Todorov, 1981) como una reflexión multiforme, semiótica y literaria. Las palabras siempre son inevitablemente "palabras de otros". Algunas palabras están inevitablemente "cargadas", "ocupadas", "habitadas" (Authier-Revuz, 1984: 100). A esta heterogeneidad del sujeto que crea un espacio enunciativo a partir de las propias palabras y de las ajenas se suman las reglas de esa misma instancia en la cual aparecen también las intenciones, las decisiones y las elecciones del enunciador. Dicho de otro modo, el sujeto de un discurso carga una intencionalidad o una orientación discursiva sobre un objeto que constituye una connotación, un tipo de significado inferencial que es percibido por el receptor.

Para llegar al nivel de la interpretación por parte del receptor es necesario que entren en funcionamiento ciertos principios que guían la construcción de inferencias que llevan a deducir el significado implícito de un enunciado teniendo en cuenta el contexto. De esta forma, por medio de la inferencia el receptor se centra en lo que se dice implícita y explícitamente. El otro concepto que creemos necesario citar es el de relevancia como la teoría sobre el funcionamiento de la comunicación humana.

Todo acto de comunicación presupone una relevancia óptima, es decir, todo hablante siempre intenta ser máximamente relevante respecto de las

5 Consideramos "elementos semánticos" a aquellos aspectos de la interpretación de enunciados regidos por reglas, codificados y que no varían con el contexto. 
circunstancias que encuadran la comunicación. Lo interesante de este otro proceso es que la interpretación se da relacionando la información recibida que se suma a los supuestos que el receptor ya posee en su memoria. Esto genera como resultado implicaciones lógicas derivadas por reglas deductivas que surgen de un determinado contexto y los enunciados del texto.

En todo caso, conviene señalar que ser relevante no es una categoría de los enunciados, sino más bien una propiedad que surge de la relación entre enunciado y contexto, esto es, entre enunciado, por una parte, y un individuo con su particular conjunto de supuestos o premisas que se emplean para interpretarlo. Estamos, pues, ante una noción de contexto, en la que se incluyen el contexto físico (formado por el entorno físico inmediato); el contexto lingüístico o contexto (formado por los enunciados anteriores) y las suposiciones que contienen informaciones de todo tipo y las que se han denominado "saber enciclopédico".

Así, es necesario presentar el siguiente esquema que hace referencia a una parte del proceso interpretativo, cuya función es completar el sentido de todo discurso y que, por la acción del receptor como agente de interpretación y otorgador de sentido, podemos hablar de interdiscurso (Bajtin: 1985).

Tabla 5

\begin{tabular}{|l|l|}
\hline implicatura & explicatura \\
\hline contenido implícito & contenido explícito \\
\hline interpretable & decodificable \\
\hline contenido inferido & contenido semántico \\
\hline
\end{tabular}

A continuación volveremos sobre los paratextos para centrarnos en una perspectiva sociolingüística con el fin de develar contenidos explícitos e implícitos. Para ello retomaremos los conceptos de implicatura como el estímulo dirigido a un interlocutor; inferencia como la información que está siendo señalada y relevancia como la relación entre enunciado e individuo. La forma inconsciente de recibir información del mundo que nos rodea. 
Tabla 6

\begin{tabular}{|c|c|c|}
\hline Contenido & Presupuesto & Sobreentendido \\
\hline [PAR1] & $\begin{array}{l}\text { - Obra del padre Montoya con datos } \\
\text { relevantes sobre las regiones del Perú y } \\
\text { del Río de la Plata } \\
\text { - Acciones benévolas de los religiosos de } \\
\text { la Compañía de Jesús con indígenas } \\
\text { - Padecimientos de jesuitas }\end{array}$ & $\begin{array}{l}\text { - Se ve lo mucho que Dios ha obrado } \\
\text { por medio del celo y trabajos y } \\
\text { predicación de los religiosos (entre } \\
\text { ellos Ruiz de Montoya) }\end{array}$ \\
\hline [PAR2] & $\begin{array}{l}\text { Obra de Montoya prometedora de } \\
\text { aumento de piedad, misericordia y } \\
\text { devoción } \\
\text { - Obra es representación de gloriosos } \\
\text { trabajos y servicios hacia Dios }\end{array}$ & $\begin{array}{l}\text { Obra de Montoya de gran } \\
\text { importancia }\end{array}$ \\
\hline [PAR3] & $\begin{array}{l}\text { Necesidad de religiosos para tareas de } \\
\text { conversión. } \\
\text { Continuar con la prédica. }\end{array}$ & $\begin{array}{l}\text { - Necesidad de evangelizadores sin } \\
\text { faltas como los jesuitas (Montoya) }\end{array}$ \\
\hline [PAR4] & $\begin{array}{l}\text { Carencia de religiosos } \\
\text { Jesuitas con caridad y ejemplaridad }\end{array}$ & $\begin{array}{l}\text { Responsabilidad de Felipe IV envío } \\
\text { de religiosos y dinero }\end{array}$ \\
\hline [PAR5] & $\begin{array}{l}\text { - Daños y perjuicios en reducciones } \\
\text { jesuitas } \\
\text { - Esclavitud de indígenas } \\
\text { - Verificación de los hechos por el } \\
\text { testimonio del padre Montoya } \\
\text { - Presunta abundancia de metales } \\
\text { preciosos en reducciones } \\
\text { Conquista Espiritual testimonio de } \\
\text { falsedad de bienes preciosos colectivos } \\
\text { y del propio Montoya } \\
\text { Pedido de visitas oficiales para tasar } \\
\text { poblados }\end{array}$ & $\begin{array}{l}\text { - Exigencia de visita para verificar la } \\
\text { verdad de Montoya }\end{array}$ \\
\hline [PAR6] & $\begin{array}{l}\text { Cese del servicio personal de indígenas } \\
\text { - Fijar tributo } \\
\text { Padrón con indígenas y nuevas tasas } \\
\text { de tributos }\end{array}$ & $\begin{array}{l}\text { Estructura de cédula real como } \\
\text { mandato. } \\
\text { Exigencia en cumplimiento de } \\
\text { Montoya }\end{array}$ \\
\hline
\end{tabular}

Toda afirmación conlleva una cierta garantía tácita de veracidad con lo que el hablante dice que lo que afirma es lo más fielmente posible de lo que quiere comunicar. Esta es la premisa básica con que deben leerse los sobreentendidos en Conquista Espiritual, ya que constituyen el resultado de premisas recuperadas por el receptor. El hablante del paratexto que venimos trabajando hace uso del lenguaje y, por lo tanto, de los discursos de manera compleja. En primer lugar destacamos la versatilidad en su propia 
construcción (SE, L) ante el hecho de decir algo, pero del mismo modo, la intención de este hablante es generar proposiciones que provoquen al destinatario a realizar un proceso de interpretación en el cual entran en juego el decir y el no decir. Así, tal como se ha presentado nuestro enunciador $E$, revelando aspectos emocionales, cognitivos, políticos, culturales y sociales, de la misma forma exige que el receptor realice lo propio: realice un proceso de formación y confirmación de hipótesis, tarea de deducción, para llegar a conclusiones implicadas.

De esta forma podemos sintetizar, en un afán de maximizar la estructura del contenido de la obra, de la siguiente forma:

\begin{tabular}{|c|c|}
\hline Explicatura & Implicatura \\
\hline Verdad & Exaltación de obras y figura de Montoya \\
\hline
\end{tabular}

Tal como venimos sosteniendo, el uso que hace Antonio Ruiz de Montoya es de una complejidad más que interesante. Aspectos históricos, sociales y culturales marcan tanto su locución como su ilocución y perlocución. En Conquista Espiritual todo se encuentra estructurado como para conformar un discurso que tiene en cuenta los siguientes aspectos:

1) Trata acerca de problemas sociales. Las cuestiones relacionadas con la evangelización y defensa de la doctrina en los poblados indígenas representan gran desarrollo en Conquista Espiritual, así también como los maltratos de los indígenas de parte de portugueses y bandeirantes. Describiendo la vulnerabilidad de los vasallos americanos del monarca, descubriendo los perjuicios hacia la Corona.

2) Las relaciones de poder se reflejan como discursos. En el paratexto de manera evidente el $\mathrm{L}$ apela a cartas y documentos legales de diferentes SE para validar las palabras en exigencia de una imperiosa solución.

3) El discurso constituye sociedad, cultura; es histórico e ideológico. La enunciación que crea Montoya refleja la construcción de espacios en donde la interacción de los padres junto con los indígenas generó comunidades con pautas propias, fruto de la síntesis cultural entre padres e indígenas que se realizó en las reducciones y las zonas aledañas de uso comunitario.

El discurso de Montoya tiene el anclaje en un determinado momento histórico del relato de los hechos, aunque hay una construcción a partir del proceso de la memoria. Lo cual hace que el receptor encuentre elementos denotados y otros connotados que tienen directa relación con cuestiones ideológicas en cuanto a concepciones utópicas, de conformación paralela de una sociedad frente a otras. 
4) El discurso es una forma de acción social porque constituye un espacio de conocimiento, información y defensa de las comunidades establecidas bajo la tutela jesuítica. A través del discurso Montoya visualiza las misiones, al indígena y al proyecto cristiano y "civilizador". Realiza un modelo de sociedad.

\section{Conclusiones}

Existen dos elementos que, según nuestra opinión, estructuran todo texto: el discurso y el locutor. Nuestro punto de partida ha sido el discurso como una realidad material escrita, como el pensamiento humano puesto por escrito. Es decir, el privilegio de la escritura por sobre el habla.

Todo discurso está conformado por proposiciones, enunciados en los que existe una tensión entre lo verdadero y falso. A partir de aquí prima la voluntad de verdad que pretende hacer frente a un sistema de características históricas, institucionalizado y modificable, que se presenta como un sistema de exclusión (Foucault, 1996). Este sistema pertenece a la propia sociedad y el discurso, como su producto, replica las tensiones que no sólo reflejan las estructuras de dominación, sino también el motivo por el cual se enfrenta al poder. De esta forma, se asumen posiciones explícitas respecto de determinados asuntos y se genera un conflicto social y político.

Ahora bien, el acontecimiento del discurso no es solamente expresión y comunicación, es también intercambio subjetivo, por el cual, como acto ilocutivo, el discurso representa un tipo de pregunta, un cuestionamiento que se espera realice una segunda persona, un lector desconocido. Esta interpelación dialógica se pretende desde varias instancias: desde la aseveración que aguarda un acuerdo, desde la reflexión que espera un diálogo consigo mismo, o desde el mandato, relacionado con la obediencia (Ricoeur, 1995).

El segundo elemento que hemos propuesto ha sido la figura del Locutor como el creador de los enunciados en la instancia de enunciación. Es el sujeto que, por el hecho de hablar, tiene un rol exclusivo y privilegiado, sin embargo, no es solamente el hablante, sino que también es el configurador de su obra. Es por ello que deja siempre su marca en lo expresado, es decir, siempre hay una autorreferencia como un elemento propio en el discurso. $Y$ es por esto que siempre hay una experiencia personal de la voz narradora sobre los sucesos. De hecho, el Locutor pretende producir conocimientos y opiniones que buscan generar procesos de cambio social y se presentan (tal como antes afirmamos) como resistencia ante los diferentes tipos de dominio.

El paratexto de Antonio Ruiz de Montoya consiste en un conjunto de discursos insertos en un acontecimiento histórico. En otras palabras, Monto- 
ya revela una concepción de la realidad histórica a partir de la construcción narrativa (basada en secuencias discursivas) que sigue una línea cronológica revelada en un orden de significación.

Montoya es el responsable de crear una situación de enunciación que se presenta polifónica al tomar diferentes sujetos empíricos y sus enunciados. Realiza una apropiación de las palabras ajenas y las emplea en una situación construida en un lugar y en un tiempo fuera del discurso originario. Es importante destacar que de los seis discursos estudiados sólo uno fue completamente producido por Ruiz de Montoya. Sin embargo, cada uno de ellos constituye situaciones de enunciación que mantienen el tono del mensaje, el tipo de relación y el vínculo entre destinador/autoridad y receptor.

\section{Referencias bibliográficas}

Anscombre, J.-C. y Ducrot, O. (1994). La argumentación en la lengua. Madrid: Gredos.

Authier-Revuz, J. (1984). "Hétérogénéité(s) énonciative(s)", en Langages, vol. $19, N^{\circ} 73$, pp. 98-111.

Bajtin, M. (1985). "El problema de los géneros discursivos", en Estética de la creación verbal. México: Siglo XXI.

Ducrot, O. (1982). Deciry no decir: Principios de semántica lingüística. Barcelona: Anagrama.

Ducrot, O. (1986). El decir y lo dicho. Polifonía de la enunciación. Barcelona: Paidós Ibérica.

Ducrot, O. y Todorov, T. (1974). Diccionario enciclopédico de las ciencias del lenguaje. Buenos Aires: Siglo XXI.

Foucault, M. (1996). La arqueología del saber. México: Siglo XXI.

Fuentes Rodríguez, C. (1995). "Polifonía y argumentación: Los adverbios de verdad, certeza, seguridad y evidencia en español", en Lexis, vol. XIX, № 1, pp. 59-81.

Grice, H. P. (1995). "Lógica y conversación", en Valdés Villanueva, L. (ed.) La búsqueda del significado. Lecturas de filosofía del lenguaje. Madrid: Tecnos, pp. 511-530.

Ricoeur, P. (1995). Teoría de la interpretación. Discurso y excedente de sentido. México: Siglo XXI.

Ruiz de Montoya, A. (1989). Conquista Espiritual del Paraguay. Rosario: Equipo Difusor de Estudios de América Latina. 
Van Dijk, T. (1999). El discurso como estructura y proceso. Estudios sobre el discurso. Una introducción multidisciplinaria. Barcelona: Gedisa.

Van Dijk, T. (1999). "El análisis crítico del discurso", en Anthropos, № 186, septiembre-octubre, pp. 23-36. 